\title{
INFRAESTRUTURA VERDE EM SUZANO, SÃO PAULO
}

\author{
Guilherme Galuppo Borba ${ }^{1}$
}

\author{
Rebecca Mendonça ${ }^{2}$
}

\begin{abstract}
RESUMO
Este artigo resume, de forma completa e concisa, o estudo preliminar de um projeto paisagístico experimental no município de Suzano, São Paulo, no âmbito da disciplina Estúdio da Paisagem do programa de pós-graduação da Faculdade de Arquitetura e Urbanismo da Universidade de São Paulo. O objetivo principal deste projeto previu o desenvolvimento de etapas de pesquisa que diagnosticaram as potencialidades e restrições dos espaços abertos públicos e privados localizados no interior dos loteamentos para o aumento da visibilidade e promoção da fruição de um Sistema de Infraestrutura Verde no município. Esse sistema, por sua vez, preconizou o aumento da sustentabilidade sócio-ecológica do entorno como um todo, considerando os elementos culturais e estéticos mais significativos da paisagem urbana. Dado o escopo abrangente deste projeto, os componentes territoriais e os elementos da paisagem foram divididos em escalas diferentes e em grupos de trabalho específicos. Isto foi possível pois contou-se com um total de 20 pessoas as quais foram subdivididas em 4 grupos que, por sua vez, mantiveram relação dialógica e conectiva entre si. Primeiramente, houve estudo teórico-conceitual sob o guarda-chuva da Infraestrutura Verde; porém, este estudo focalizou a coleta de dados empíricos socioculturais e ambientais - visita de campo, uso de questionário e fotografias - de forma a experimentar com possibilidades projetuais pautadas na experiência do vivido e do presente. Ao final, este estudo concluiu as preliminares para aWord did not find any entries for your table of contents. implantação de um ecossistema urbano sustentável em zonas residenciais no município de Suzano, São Paulo, maximizando as funções ecológicas, paisagísticas e culturais dos espaços estudados.
\end{abstract}

PALAVRAS-CHAVE: Sistema de Infraestrutura Verde. Paisagem Urbana. Suzano.

\section{GREEN INFRASTRUCTURE IN SUZANO, SÃO PAULO}

\author{
ABSTRACT \\ This article summarizes, in a complete and concise manner, the preliminary study of an experimental \\ landscape design in the city of Suzano, São Paulo, under the discipline Landscape Studio which is

\footnotetext{
${ }^{1}$ Formado em Geografia pela FFLCH-USP, mestre em Paisagem e Ambiente na FAU-USP com bolsa FAPESP; galuppo82@hotmail.com

${ }^{2}$ Formada em Arquitetura e Urbanismo pela FAAP, mestre em Paisagem e Ambiente na FAU-USP; rebeccamendonça@gmail.com
} 
part of the graduate program of Landscape Studies at FAU-USP. The main objective of this project included the development of research steps that diagnosed the strengths and weaknesses of public and private open spaces within the blocks and the increased visibility and promotion of the enjoyment of a Green Infrastructure System in the city. This system, in turn, called for increased social and ecological sustainability of the environment as a whole, considering the cultural and aesthetic elements most significant to the urban landscape. Given the broad scope of this project, the territorial components and municipal landscape elements were divided into different scales and in specific working groups. This was possible because there was a total of 20 individuals who were divided into 4 groups which, in turn, maintained satisfactory relationship with each other. Firstly, a theoretical and conceptual study was carried out under the umbrella of the Green Infrastructure; However, this study focused on the collection of socio-cultural and environmental empirical data - fieldwork, use of questionnaire and photographs - in order to experiment with projective possibilities guided by the experience of daily life. Finally, this study concluded the first steps for the implementation of a sustainable urban ecosystem in residential areas in the city of Suzano, São Paulo, maximizing the ecological, landscape and cultural functions of the spaces in question.

KEY-WORDS: Green Infrastructure System. Urban Landscape. Suzano.

\section{INFRAESTRUTURA VERDE EN SUZANO, SÃO PAULO}

\section{RESUMEN}

Este artículo resume, de manera completa y concisa, el estudio preliminar de un diseño experimental del paisaje en la ciudad de Suzano, Sao Paulo, en el marco del programa de postgrado en paisaje bajo la disciplina Estudio del Paisaje en la FAU-USP. El objetivo principal incluyó el desarrollo de medidas de investigación que diagnostican el potencial y las limitaciones de los espacios abiertos públicos y privados dentro de los asentamientos a la mayor visibilidad y promoción del disfrute de un Sistema de Infraestructura Verde de la ciudad. Este sistema pidió una mayor sostenibilidad social y ecológica del medio ambiente en su conjunto, teniendo en cuenta los elementos culturales y estéticos más significativos del paisaje urbano. Dado el amplio alcance de este proyecto, los componentes territoriales y elementos del paisaje municipales fueron divididos en diferentes escalas y en grupos de trabajo específicos. Esto fue posible porque contó con un total de 20 individuos que fueron divididos en 4 grupos que, a su vez, mantuvieron relación satisfactoria entre sí. En primer lugar, hubo un estudio teórico y conceptual sobre la Infraestructura Verde; sin embargo, este estudio se centró en la recolección de datos empíricos socio-culturales y ambientales - visita de campo, cuestionario y fotografías - para experimentar con las posibilidades proyectivas guiadas por la experiencia de la vida y del presente. Por último, este estudio concluyó las bases para la aplicación del ecosistema urbano sostenible en las zonas residenciales en Suzano y la maximización de la ecología, el paisaje y las funciones culturales de los espacios estudiados.

PALABRAS-CLAVE Sistema de Infraestructura Verde. Paisaje Urbano. Suzano.

\section{INTRODUÇÃO}

\section{É lugar comum proferir que as áreas verdes são importantíssimas para} nosso habitat urbano pois possuem funções social, educativa, ecológica e estética. 
No entanto, a falta destes locais, principalmente nos centros urbanos, acaba desencadeando um efeito dominó no desenho do espaço das cidades, que se tornam mais quentes e menos acolhedoras em função do desequilíbrio ambiental ocasionado (FARR, 2008). A sociabilidade é outro aspecto ressaltado, uma vez que a construção as praças, jardins e áreas de lazer, além de servirem para regular o ambiente, também aproximam as pessoas e contribuem para a diminuição da violência. A preocupação com a harmonização do espaço urbano acompanha a história do desenvolvimento das cidades. Hoje, existe a compreensão de que homem, natureza e habitação fazem parte dessa realidade, devendo haver um equilíbrio na distribuição desses espaços que servem de circulação para as cidades (HERZOG, 2010). São Paulo figura, já há longa tempo, como uma das maiores aglomerações urbanas do mundo, com um déficit de terras verdes alarmante e problemas socioambientais diversos. Não obstante, a qualidade de vida do citadino fica significativamente prejudicada quando esses aspectos se agravam. As cidades periféricas da metrópole - caso de Suzano - encontram-se em posição ainda pior no que tange o ordenamento urbano e sua infraestrutura verde. Mesmo que haja ocorrido enorme avanço na literatura global sobre soluções, técnicas e projetos verdes em grandes metrópoles, vê-se um retrocesso e/ou paralisia no planejamento urbano e seus componentes ambientais e paisagísticos. Em suma, a problemática socioambiental na metrópole, mesmo que aparentemente desgastada, mantem-se viva e premente na agenda das transformações necessárias do presente.

\section{OBJETIVOS}

Tento em vista esta colocação, o objetivo principal deste estudo foi construir um projeto paisagístico experimental sobre o município de Suzano, São Paulo, o qual prevê o desenvolvimento de planos e projetos que diagnosticam as potencialidades e restrições dos espaços abertos públicos e privados para uma infraestrutura verde e o aumento da sustentabilidade sócioecológica, considerando os elementos culturais e estéticos mais significativos da paisagem urbana. Dado o escopo abrangente deste projeto, os componentes territoriais e os elementos da 
paisagem do município foram divididos em escalas diferentes e grupos de trabalho específicos, mantendo porém relação dialógica e conectiva entre eles. Assim, este estudo debruçou-se sobre as possibilidades de implantação de um ecossistema urbano sustentável em zonas residenciais, isto é, que maximizasse as funções ecológicas, paisagísticas e culturais dos espaços abertos localizados no interior dos loteamentos, promovendo maior visibilidade e fruição de um sistema de infraestrutura verde geral no município. Não tivemos a pretensão de abarcar toda a bibliografia, metodologia e matrizes deste tema, mas foco foi dado à visita de campo e à coleta de opiniões dos moradores para que os pesquisadores pudessem experimentar com possibilidades de projeto na construção de um sistema verde que fosse condizente com os aspectos socioculturais e ambientais do local estudado.

\section{METODOLOGIA}

Em linhas gerais, a infraestrutura verde consiste em redes multifuncionais de fragmentos permeáveis e vegetados, preferencialmente arborizados, incluindo ruas e propriedades públicas e privadas que estão interconectados e que reestruturam o mosaico da paisagem. Busca a manutenção ou o reestabelecimento de processos naturais e culturais que garantem a qualidade de vida urbana (BENEDIC, 2006; AHERN, 2007). A infraestrutura verde considera os aspectos geobiofísicos mas também o uso e ocupação dos espaços ao longo do tempo, atribuindo-lhes função, forma e conteúdos (AHERN, 2007).

Dessa forma, tendo em vista o lado do uso e da criação antrópica de um habitat urbano almejado, vemos relevante obter uma maior aproximação do cotidiano vivido nos espaços para, posteriormente, lançar bases para transformações paisagísticas. Com os resultados, teríamos um quadro vivido, real e presente das condições sociais e materiais para a implantação de transformações que visassem a melhoria da qualidade de vida dos moradores em função da relação com a paisagem e o ambiente.

Pelo fato deste trabalho estar intimamente ligado a uma experimentação livre e dinâmica de processos socioambientais, a metodologia para apreensão do 
objeto, coleta de dados e análise dos resultados manteve-se simples e direta. Isto se deu porque colocamos ênfase nas informações opinativas dos moradores em relação aos espaços possíveis de receber uma infraestrutura verde e nas qualidades físicas, ambientais e estruturais dos espaços. Portanto, iniciamos o estudo com uma breve caracterização da área de estudo, buscando delimitar e estabelecer correlações entre o substrato físico - ruas, calçadas, edificações, terrenos baldios, parques, plantações, florestas, etc. - e as funções, usos e importância destes para a população, tendo as imagens de satélite, fotografias, mapas e documentos oficiais como base para esse levantamento. A segunda etapa caracterizou-se pelos métodos empíricos que conseguissem promover leituras da paisagem urbana dentro de um território escolhido, considerando os conteúdos sociais, objetivos e subjetivos refletidos e descritos na caracterização da área de estudo. Para tanto, pensamos no potencial da comunicação e, neste caso, na livre conversa com as pessoas, na interação social, e também no uso de questionários. As duas primeiras basearam-se na observação participante, que tem sido definida como um "período de intensa interação social entre pesquisadores e sujeitos, no meio desses últimos, durante o qual coletam-se dados, na forma de notas de campo, de uma maneira sistemática e não-reativa" (BOGDEN, 1972, apud SELLTIZ, 1987, p. 111). Também optamos pelo uso de um questionário que buscasse informações básicas e complexas da vida e ideias dos moradores locais. Tentamos estabelecer um certo equilíbrio quanto às questões mais negativas e mais positivas, às de fatos e opiniões, quanto à complexidade e/ou possibilidades de sutileza das respostas, às abertas e fechadas (SINGLY, 2008). Seu objetivo principal foi o de estabelecer, em ordem de importância, os anseios, visões e opiniões dos moradores sobre a qualidade de vida na cidade e sua relação com a presença e/ou falta e/ou características positivas e negativas dos espações e da paisagem. Finalmente, o uso de fotografias serviu para a análise e elaboração de proposições paisagísticas relacionadas a implantação de uma infraestrutura verde possível e coerente. 


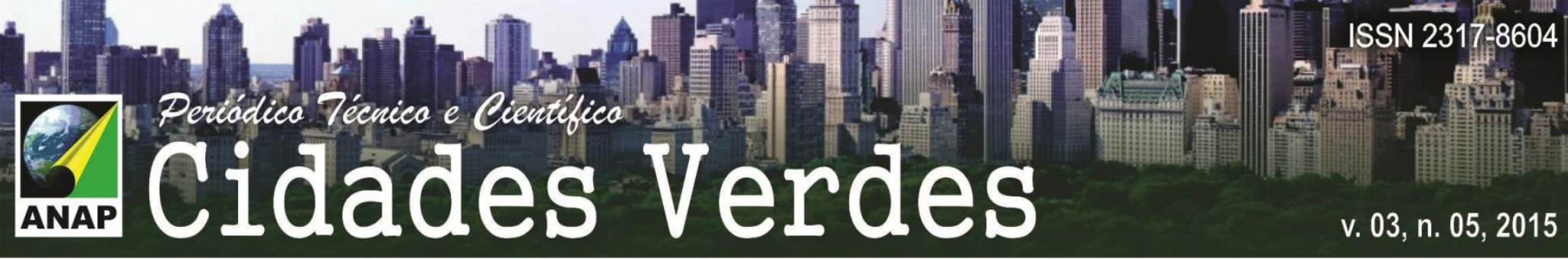

Figura 1: Área Central de Suzano com delimitação da área de estudo

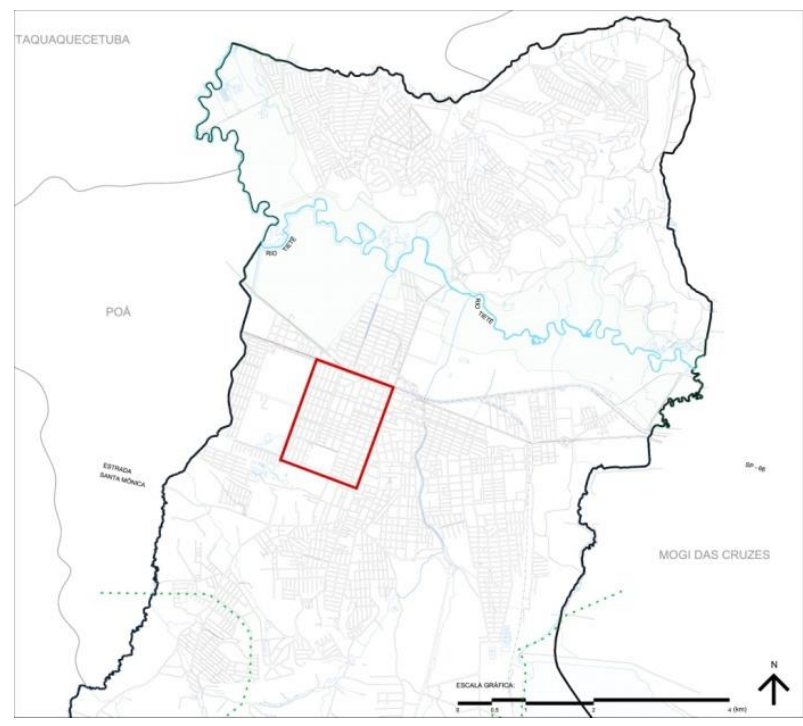

Fonte: SEMPLA, 2002

\subsection{Visita a campo - diagnóstico socioambiental}

Fizemos uma primeira visita a Suzano a fim de levantarmos um diagnóstico abrangente das potencialidades e restrições do município relacionadas a uma possível implementação de sistemas de infraestrutura verde. Conversamos com Michele Sá Vieira, secretária da Secretaria do Meio Ambiente de Suzano e com o secretário de obras, os quais nos mostraram um pouco da extensão territorial de Suzano com as questões mais prementes além de um apanhado histórico e político. Fica claro, portanto, que este trabalho é um recorte específico de uma realidade mais complexa nos vários âmbitos das problemáticas socioeconômicas e ambientais de um município da macro zona metropolitana de São Paulo.

Também fizemos uma segunda visita a campo mas, desta vez, nosso olhar se ateve à área previamente delimitada e buscamos extrair informações mais específicas e palpáveis. Com a ajuda de imagens de satélite, mapas, fotografias, questionários e entrevistas com a população do local, coletamos dados importantes para o levantamento das potencialidades e restrições da área numa escala menor e consequentemente mais detalhada. Em linhas gerais, pesquisamos 0 
posicionamento da população local frente a questões relacionadas à paisagem, ao ambiente e à qualidade de vida. Fotografamos situações críticas, mapeamos os espaços livres públicos e privados com potencial para a implantação de um sistema de infraestrutura verde e percorremos, a pé ruas, praças, calçadas e até quintais de propriedades particulares no intuito de maximizar a experiência e a captação de informação.

\subsection{Síntese Analítica dos Resultados}

Não é nosso intuito utilizar estes dados quantitativos de forma determinista e/ou pragmática. No entanto, é possível termos uma ideia de alguns posicionamentos e questionamentos da população local frente às questões pertinentes deste estudo ${ }^{4}$. Muitos dos entrevistados não possuíam alto grau de instrução, dificultando a interpretação das questões por parte dos entrevistados. No geral, constatou-se que a população local não está tão desconte com a situação da paisagem, praças e áreas verdes da área delimitada, avaliando-as majoritariamente como regulares e boas. Contudo, os pesquisadores não compartilham da mesma opinião, exemplificando uma situação em que talvez haja falta de acesso da população às qualidades paisagísticas e ambientais de outras cidades brasileiras e/ou do exterior. Apesar das ruas terem sido classificadas como sendo regulares a ótimas, a arborização e as calçadas foram avaliadas num nível mais inferior, demonstrando condições ruins a péssimas, majoritariamente. Dos entrevistados, $52 \%$ responderam possuir forte preocupação com o meio ambiente e $42 \%$ possuem preocupação mediana. Isso nos levaria a crer que esta população poderia transformar-se num grupo engajado e coeso de luta de melhorias ambientais. Apesar de apenas 52\% dessa mesma população reciclar seu lixo atualmente, houve unanimidade em iniciar a reciclagem do lixo contanto houvesse um incentivo maior do governo, colocando lixeiras recicláveis perto das casas, por exemplo. Ademais, a ideia de transformar o bairro em um "pulmão verde", de permeabilizar o solo e verdejar mais intensamente os quintais das casas e terrenos ociosos e de participar

\footnotetext{
${ }^{4}$ Para a visualização dos resultados obtidos, verificar questionários e gráficos no Apêndice, da página 17 à 19.
} 
ativamente de um mutirão de qualificação ambiental do espaço público mostraramse positivas e favoráveis. Em relação ao fomento de elementos artísticos nesse projeto, $92 \%$ dos entrevistados consideram-no de bom à excelente. Nesse sentido, era de se esperar que a maioria dos entrevistados estivesse bastante insatisfeita com a atuação da Secretaria do Meio Ambiente de Suzano, qualificando-a como Péssima, Ruim e Regular, majoritariamente. Portanto, dadas as devidas proporções da pesquisa de campo, percebemos que há forte relevância na implantação do projeto de infraestrutura verde na zona central de Suzano por parte da população local, a qual mostrou-se preocupada e engajada nas melhorias ambientais e paisagísticas, facilitando uma possível intervenção no espaço.

\section{ESPAÇOS DE AÇÃO}

Considerando nossa tentativa de implantação de espaços abertos, públicos e privados, que sustentem serviços sociais e ambientais mais valiosos para o uso e apropriação de uma cidade mais vivível, propomos algumas ações, de caráter cívico e público, listadas abaixo.

\subsection{Espaços abertos intraquadra}

- Manutenção, tratamento e desenvolvimento das funções ecológicas dos espaços abertos (quintais, estacionamentos, terrenos baldios, corredores, etc) e que já possuem certa relevância ecológica (solo exposto, por sua permeabilidade existente, gramíneas, arbustos, árvores, cursos d’água, etc.).

- Implantação de novos espaços abertos que não possuem funções ecológica atualmente mas que têm alto potencial para tal. A transformação do uso e apropriação de tais espaços dependerá em grande escala da atuação do poder público com incentivos e/ou restrições e da participação dos moradores nessa causa (ex. Linhão, lajes de prédios, estacionamentos, etc. Ver figura 3) 


\subsection{Calçadas e passeios}

- Permeabilização e arborização. Possibilidades de arborização e tratamento paisagístico. Elementos culturais e artísticos podem fazer parte dos elementos estéticos a serem elencados pelas diferentes instâncias de influencia: poder público, universidade e comunidade civil. Reciclagem de resíduos domésticos e compostagem de lixo orgânicos.

\subsection{Muros e fachadas}

- Tratamento ambiental e paisagístico. Pinturas, grafites, ladrilhos e outras intervenções artísticas podem ser pensadas para esses espaços. Remando a favor das funções ecológicas, pensar na possibilidade de trepadeiras e arboretos para esses espaços: "ecoparedes".

\subsection{Ruas e vias}

- Nas avenidas principais, pensar na implementação de um sistema cicloviário, atentando para os bicicletários e segurança no trânsito. Nas ruas residências, em sua maioria de paralelepípedo, projetar um passeio de asfalto permeável que possa ser utilizado ludicamente pelos moradores do entorno, facilitando o uso de bicicletas, patins, skates, carrinhos de bebê e até caminhadas e corridas de cooper.

\subsection{Cursos d'Água}

- Propor a requalificação de um córrego do entorno e sua conexão com a malha urbana. Projeto de tratamento ecológico e paisagístico para suas margens, otimizando o terreno plano para ciclovias e passeios para caminhada e cooper. Áreas de estar e de recreação podem trazer revitalização e maior controle da população sobre o espaço público. lluminação, bebedouros, sanitários e outras estruturas de utilização pública dependeriam em grande parte do incentivo do poder público, que neste caso, exerceria forte influência na sua implementação. 


\section{PROPOSTAS DE AÇÃO}

Com base no diagnóstico das potencialidades e restrições da área estudada, elaboramos um esquema simples de propostas específicas para alguns espaços livres com alto potencial ambiental e paisagístico. Levamos em consideração os estudos geográficos, ambientais e políticos da área assim como as opiniões dos moradores locais através de entrevistas e questionários. A implantação de um sistema de infraestrutura verde para os espaços abertos intraquadra desta área é foco essencial das propostas a seguir.

\subsection{Quadra-Verde}

Verificamos a existência de quadras residenciais que já abrigam espaços abertos intensamente vegetados, como é o caso da quadra tipo 1 (ver figura 2). Outras quadras, caso tipo 2, possuem espaços abertos restritos, exíguos e de intensa utilização doméstica (ver figuras 3). Dessa forma, estabelecemos a proposta de maximizar o potencial ecológico desses espaços, intensificando o verde intraquadra assim como nas ruas contíguas. Telhados verdes possuem certa dificuldade de implantação mas exercem função climática e ambiental altamente eficiente. Sua utilização dependeria em grande escala de incentivos fiscais e conscientização dos moradores.

As quadras ao lado representam a possibilidade de implantação de uma infra estrutura verde intraquadra nos dois tipos característicos de quadras situadas na zona central de Suzano. As partes cinzas representam as edificações existentes e o verde representa os espaços abertos público e privado com potencial ecológico. Nota-se a dificuldade de implantação do verde em quadras intensamente edificadas. Porém, esses espaços ainda existem e podem carregar funções ambientalmente sensíveis. A utilização de gramíneas, arbustos, árvores, trepadeiras e mesmo o solo exposto ajudariam nessas funções, além das climáticas e faunísticas. 


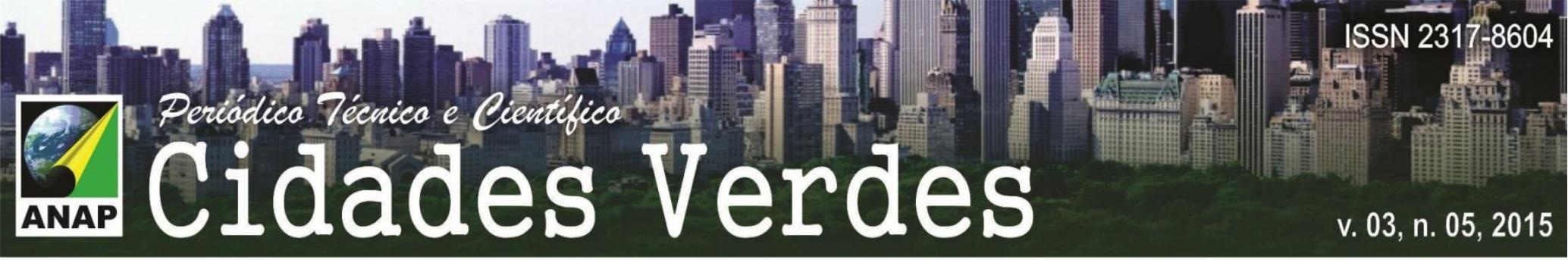

Figura 2: Quadra Tipo 1

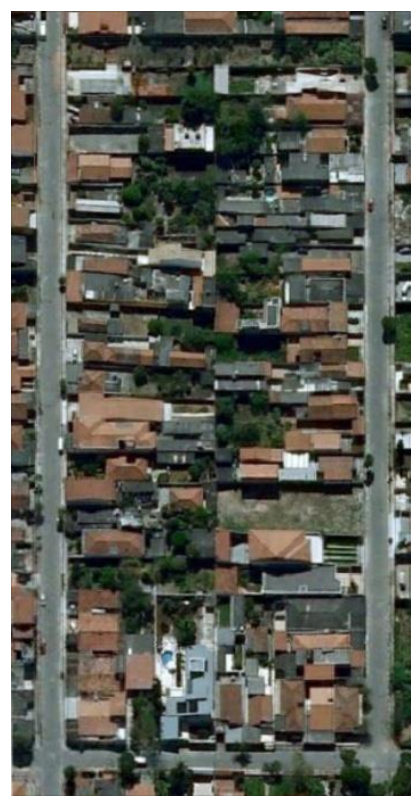

Fonte: Google Earth, 2012

Figura 4: Proposta Quadra Tipo

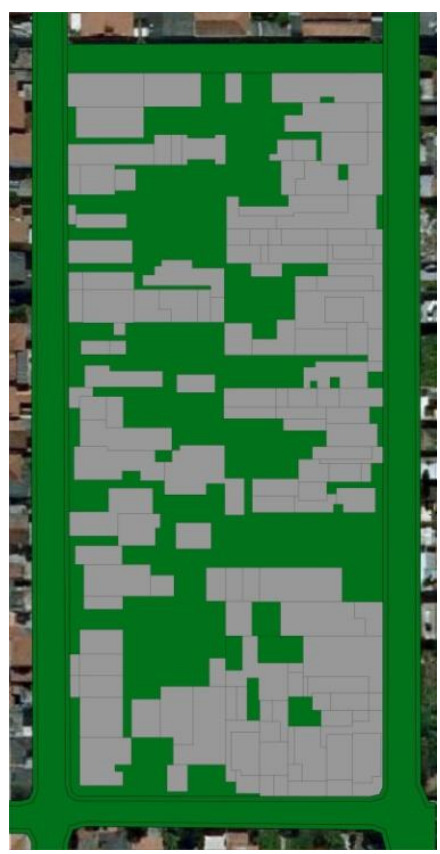

Fonte: Google Earth, 2012
Figura 3: Quadra Tipo 2

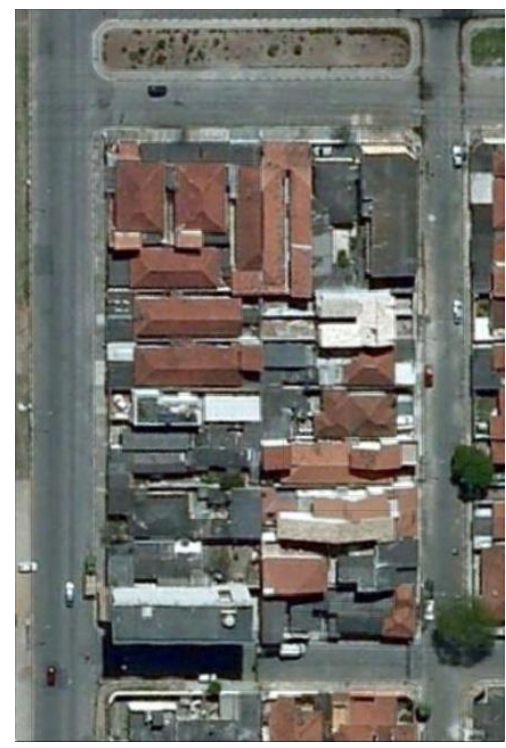

Fonte: Google Earth, 2012

Figura 5: Proposta Quadra Tipo

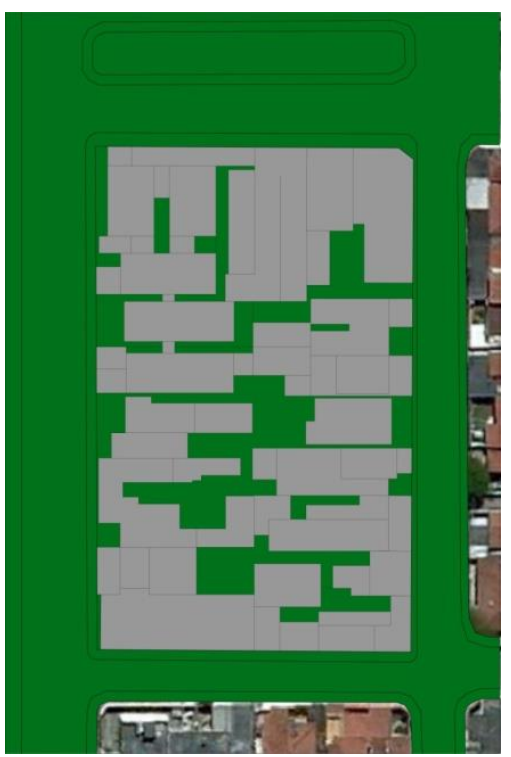

Fonte: Google Earth, 2012 


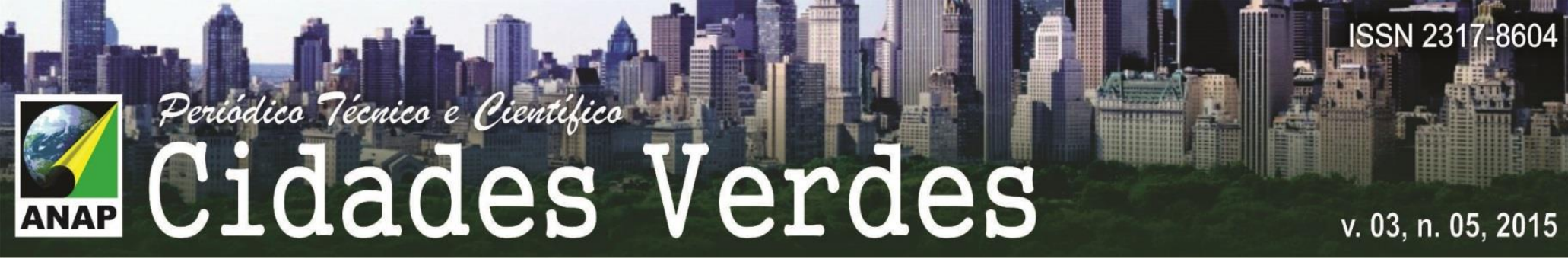

\subsection{Passeio do Linhão}

O linhão de energia que corta a zona central da cidade poderia oferecer um passeio verde, de convivência e possível comércio. Áreas de convivência, ciclovias, passeios e outras utilidades podem fazer parte desta proposta. A seguir há dois cortes esquemáticos que possibilitam a visualização deste passeio (ver figuras 6 e 7).

Figura 6: Perfil 1

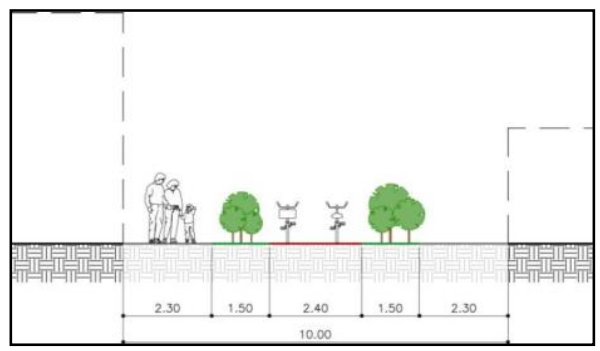

Fonte: Rebecca Mendonça, 2012
Figura 7: Perfil 2

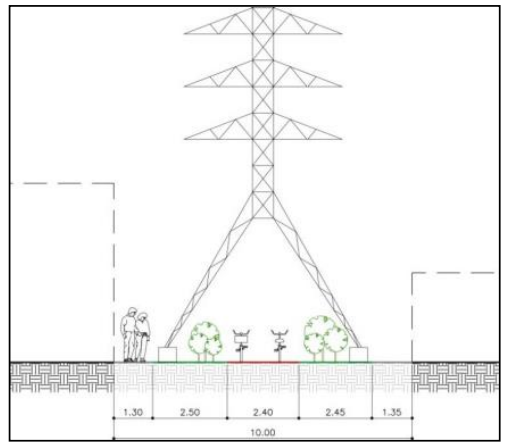

Fonte: Rebecca Mendonça, 2012

\subsection{Corredores Verdes - Eixos Principais e Secundários}

Como já havíamos proposto, a implantação de um sistema de infraestrutura verde também se dá através das vias de comunicação e transporte pela cidade. Portanto, a utilização de ciclovias, calçadas mais largas, arborização e bio-valetas foi proposta a fim de incentivar meios mais sustentáveis de percorrer a cidade e de estabelecer maior conforto climático e paisagístico para a área. Nota-se que esta proposta de comunicação viária prioriza os pedestres e ciclistas, sem banir por completo o uso de veículos automotores. No entanto, um projeto de cidade sustentável, ecológica e mais humana dependerá fortemente de transformações estruturais na implementação de políticas públicas mais abrangentes e eficazes no país. 


\section{CONCLUSÃO}

A implementação de um sistema de infraestrutura verde para uma área específica de uma cidade em expansão como Suzano se mostra delicada porém cheia de possibilidades. Ao mesmo tempo em que a população local mantém estreita ligação com o espaço vivido, deixa de acreditar na sua melhoria em função de tantas transformações urbanas mal concebidas ao longo dos anos. $O$ trabalho minucioso de educação e conscientização ambiental dos moradores deve iniciar e fundar todos os pilares que viabilizariam a implementação de tal estrutura verde, já que o resultado do questionário demonstra falta de informação dos respondentes mas, ao mesmo tempo, vontade intrínseca à melhoria estética e ambiental da cidade. O tipo, a distribuição e o uso das estruturas urbanas de Suzano colocam muitos entraves para se atingir todas as características ideials de uma infraestrutura verde, principalmente aquela preconizada na literatura científica global. Contudo, sabe-se que a realidade das cidades brasileiras frequentemente apresentam rigidez e obstáculos para transformações estruturais e também comportamentais, já que o último também depende de políticas educacionais e ambientais advindas do poder público. Por isso, tentou-se diagnosticar estes dois aspectos para que pesquisássemos o potencial que tinham na recepção de projetos urbanísticos e paisagísticos. Os resultados demonstram que, apesar das dificuldades, um sistema de infraestrutura verde pode ser implantado em cidades que não receberam qualquer planejamento urbanístico e/ou paisagístico e que a articulação de diferentes atores é fundamental para viabilizar estas transformações. Ao fim e ao cabo, é o papel da universidade pensar crítica e criativamente nas transformações possíveis no espaço urbano e é nesse caminho que este estudo pretendeu seguir.

\section{REFERÊNCIAS}

AHERN, Jack. Sustainability, Urbanism and Resilience. Palestra na Primeira Conferência de Humanidades e Indústria Criativa, Universidade de Tecnologia Nacional Chyn-Yi, Taichung, Taiwan, 4 de junho de 2009. pp. 4-22.

BENEDICT, Mark A. Green infrastructure: linking landscapes and communities. Washington D.C.:Island Press, 2006. 


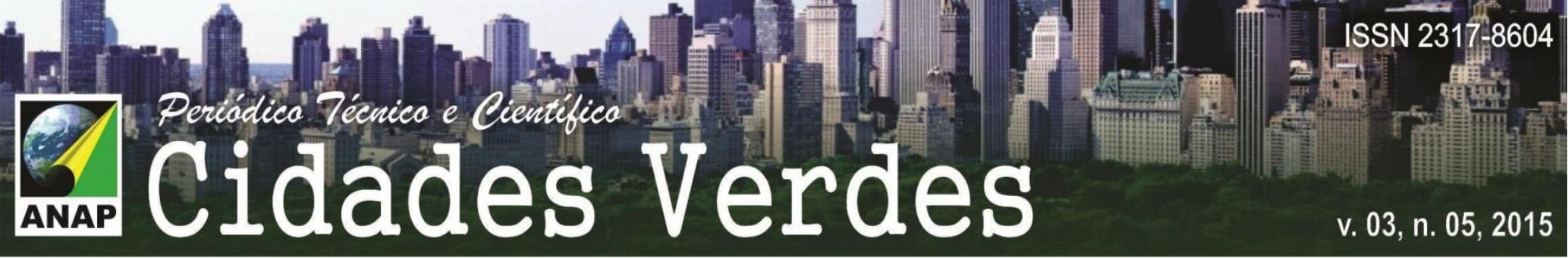

FARR, David. Sustainable Urbanism - Urban design with nature. John Wiley \& Sons, Inc. Hoboken, NJ, 2008.

HERZOG, Cecília Polacow; ROSA, Lourdes Zunino. Infraestrutura Verde: Sustentabilidade e resiliência para a paisagem urbana. Revista LABVERDE, [S.I.], n. 1, p. 92-115, set. 2010. ISSN 2179-2275.

SELLTIZ, COOK, WRIGTHSMAN. Métodos de pesquisa nas relações sociais. 2.Ed. São Paulo: EPU, 1987, V.2.

SINGLY; de François. L'enquête et ses Méthodes. Le Questionnaire. Armand Colin, 2008. 


\section{APENDICE A - Questionário sobre Infraestrutura verde- projeto intraquadra}

1. Há quanto tempo mora por aqui?

2. Como você qualificaria a arborização do entorno?

Péssima_Ruim___Regular__Bo____Excelente

3. Como você qualificaria as calçadas do entorno?

Péssima_Ruim___Regular__B__Excelente

4. Como você qualificaria as ruas do entorno?

Péssima_Ruim___Regular__Boa___Excelente

5. Como você qualificaria as praças e áreas verdes do entorno?

Péssimas_Ruins___Regulares__Boas___Excelentes

6. Como você qualificaria a paisagem do entorno?

Péssima_Ruim___Regular__Boa___Excelente

7. Você gostaria que houvesse mais plantas, árvores e flores no seu bairro?

Sim_ Não

8. Qual a sua preocupação com o meio ambiente?

Forte___ Mediana____ Fraca

9. Você recicla seu lixo? Sim

Não

10. Se houvesse lixeiras para o lixo reciclado na frente da sua casa, você reciclaria?

Sim Não

11. Como você qualificaria a atuação da Secretaria do Meio Ambiente de Suzano?

Péssima_Ruim___Regular_Br_Boa_r_Ente

12. Se a Secretaria do Meio Ambiente e os moradores do entorno fizessem um projeto de requalificação ambiental de seu bairro (arborização, permeabilização de calçadas, lixo reciclável, etc) e você precisasse participar ativamente nele, você o faria?

Sim Não

13. Se parte desse projeto incluísse arborização e permeabilização do solo nos quintais das casas. Você o faria na sua própria casa e bancaria os gastos? Sim Não

14. O que você acha da idéia de transformar o bairro em um grande "pulmão verde" do município? Péssima_Ruim___Regular___Boa___Excelente

15. O que você acha da idéia de haver elementos artísticos no bairro, como exemplo, muros desenhados ou aladrilhados, calçadas coloridas, fachadas grafitadas, etc?
Péssima
Ruim
Regular
Boa
Excelente 


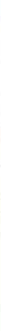

16. Se os moradores e o poder público organizassem um mutirão para trazer maior beleza estética para o bairro, você participaria? Sim Não

17. Contribuiria financeiramente com o projeto? Sim Não 


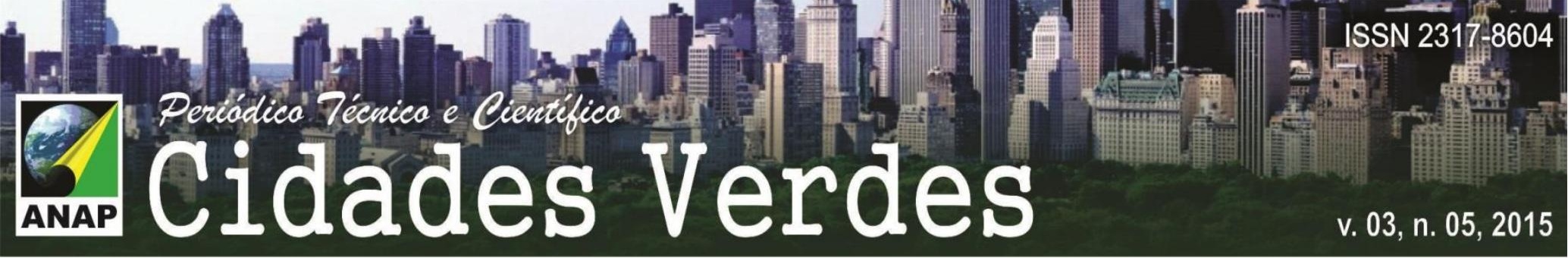

\section{APENDICE B - Resultados do questionário em forma de gráfico (porcentagem)}

Figura 1: Conjunto de 14 gráficos mostrando os resultados do questionário
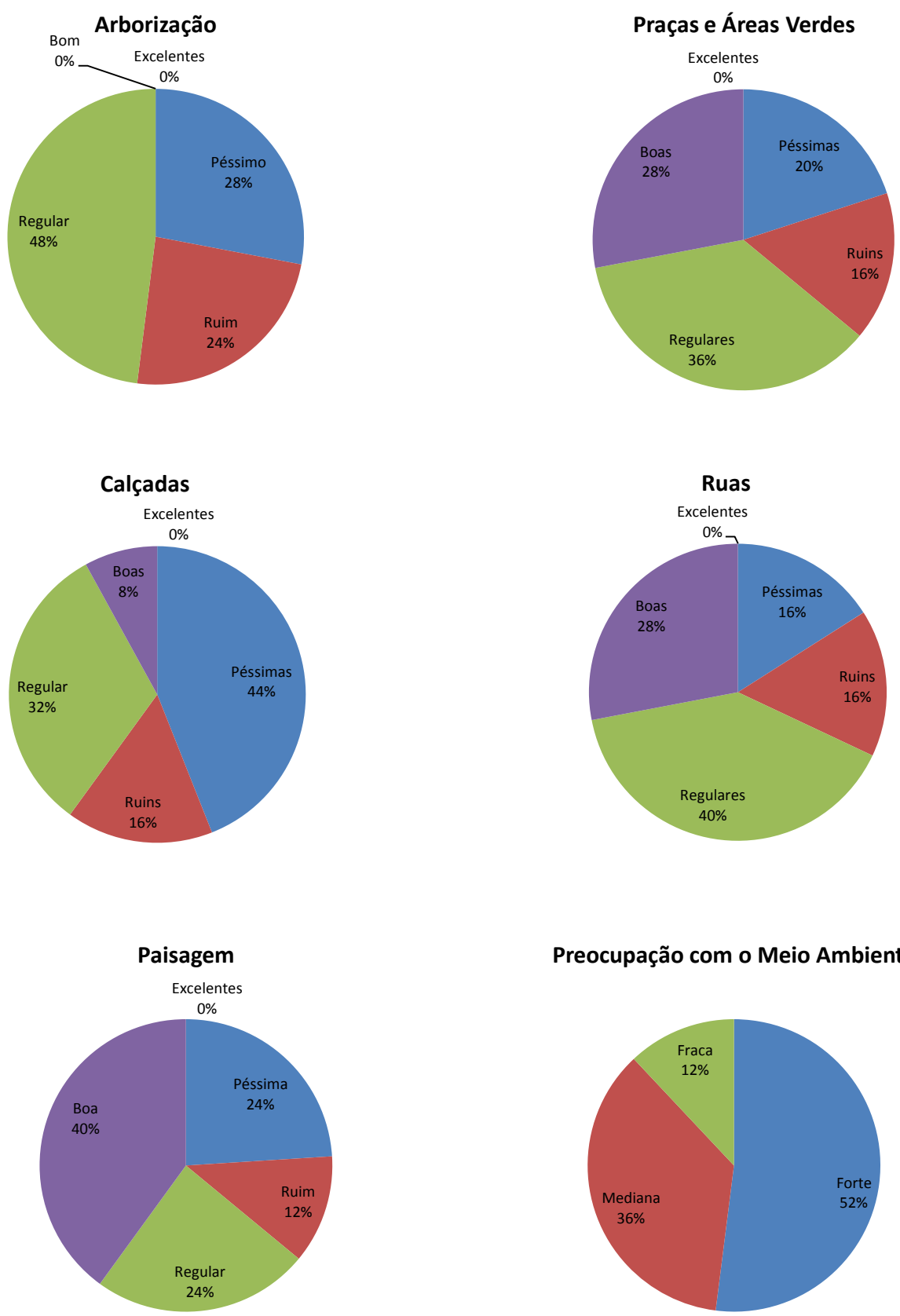

Preocupação com o Meio Ambiente

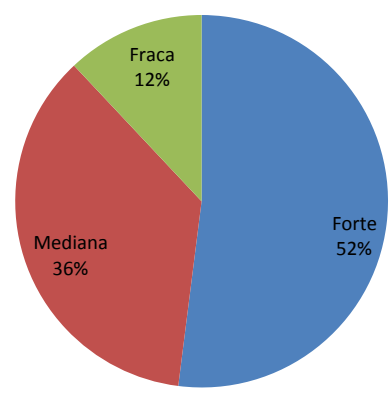



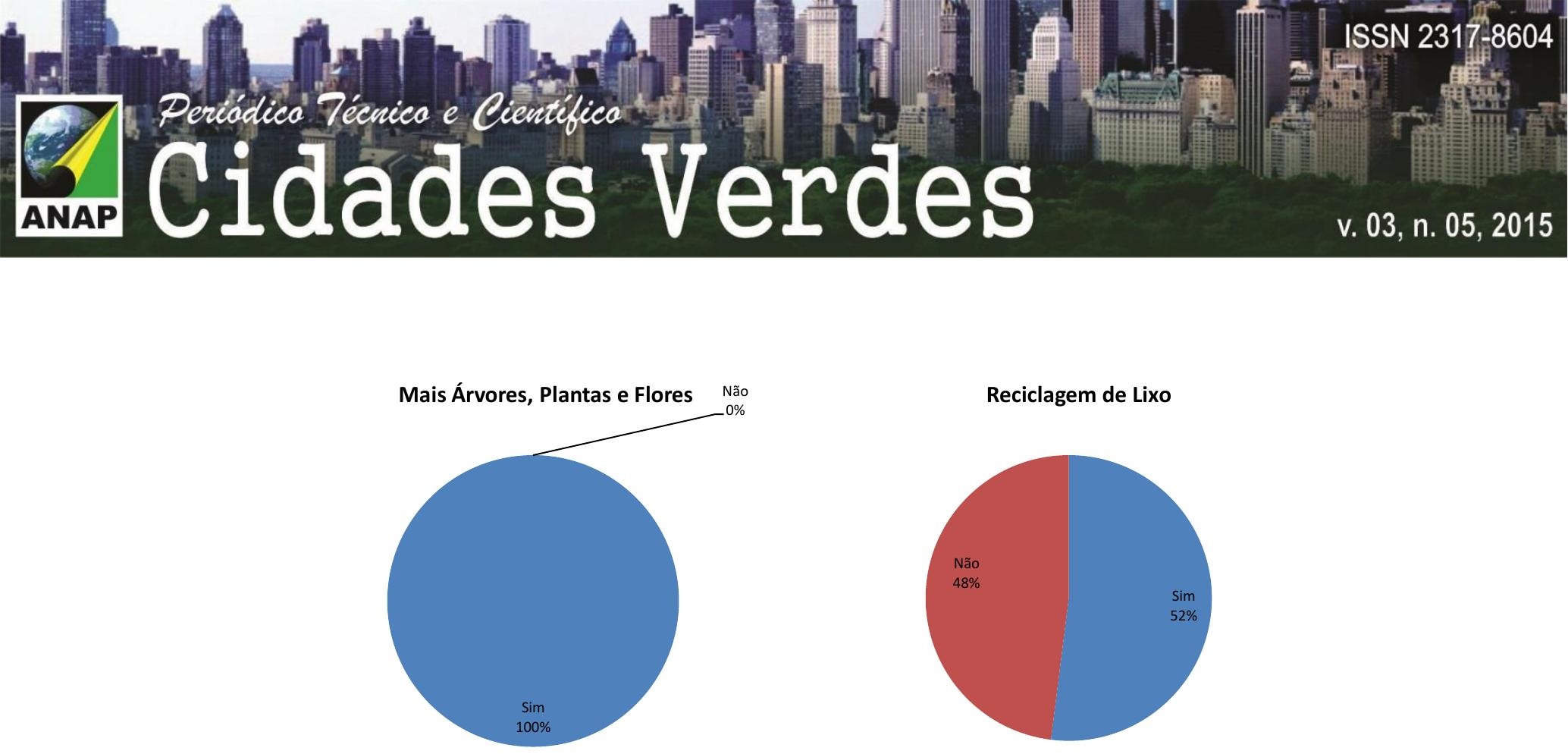

Quem reciclaria o lixo se houvesse lixeiras do lado de casa

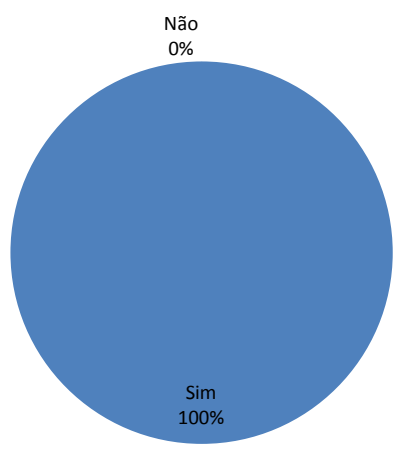

Bairro como "Pulmão Verde"

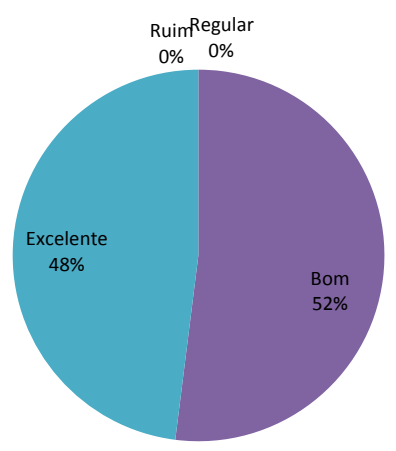

Atuação da Secretaria do Meio Ambiente de Suzano

Permeabilização do Solo e Arborização de Quintais
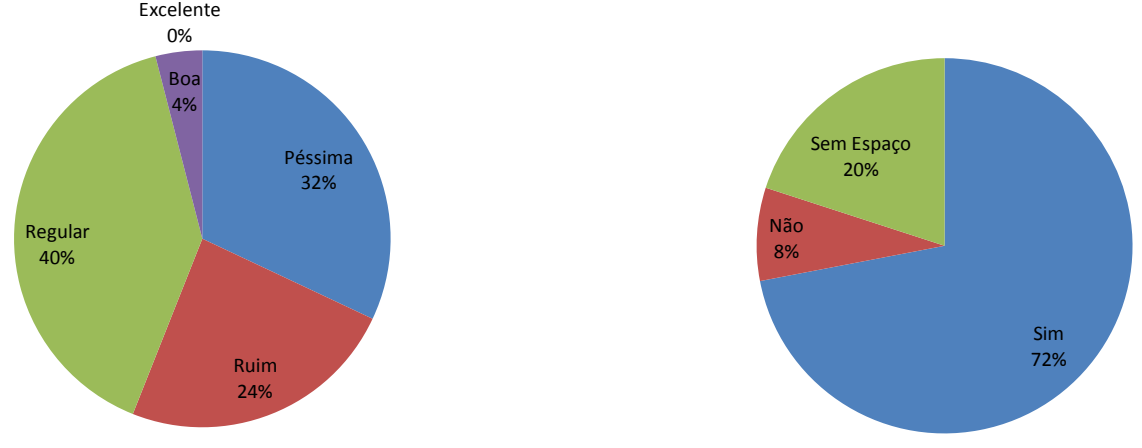


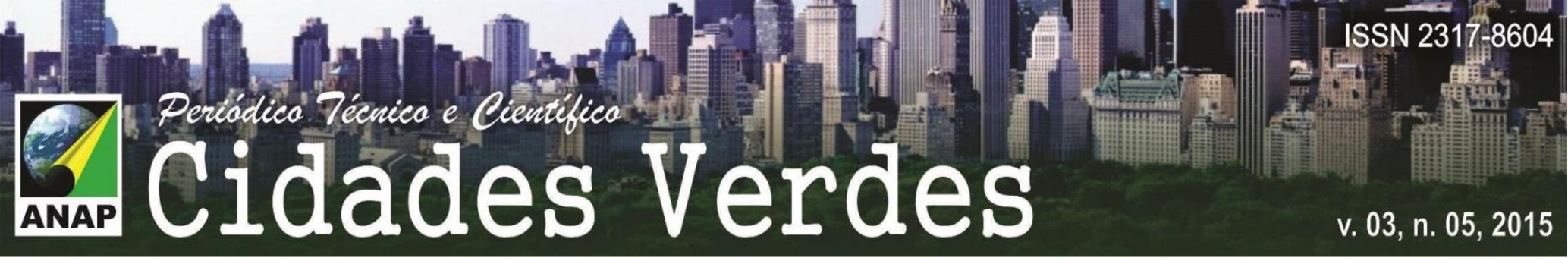

Participação do ProjetoMutirão de Requalificação Ambiental da Área

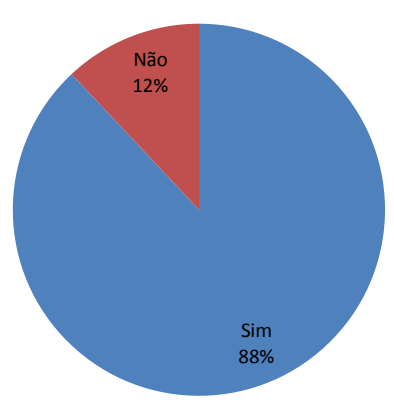

Opinião sobre o Fomento de Elementos Artísticos no Bairro

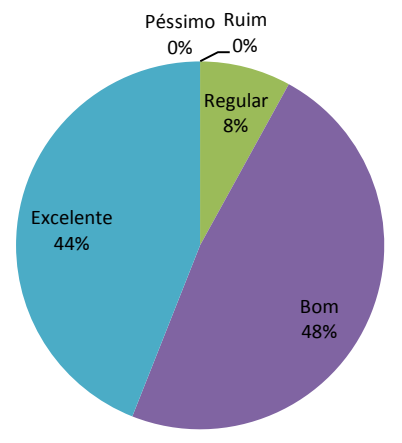

